\title{
El historiador como exorcista
}

\author{
$\approx$ \\ Historian as an Exorcist \\ Pedro Espinoza Meléndez \\ El Colegio de México \\ México \\ Correo: pespinoza@colmex.mx \\ DOI: 10.48102/hyg.vi57.184
}

Reseña recibida: $20 / 08 / 2020$

Reseña aceptada: I6/02/202 I

González, Fernando. Secretos fracturados. Estampas del catolicismo conspirativo en México, México, Herder, 2019. ${ }^{1}$

$\mathrm{E}_{\mathrm{cen}}^{\mathrm{n}} \mathrm{d}$ septiembre de 2017 tuvieron lugar una serie de eventos Occidente (ITESo), la universidad jesuita de Guadalajara, que giraron alrededor de un foro sobre la despenalización del aborto, organizado por estudiantes de esa institución. De acuerdo con varios medios, la actividad estuvo a punto de cancelarse debido a la presión ejercida por grupos Pro-Vida. Gracias a la movili-

${ }^{1}$ Esta reseña es la versión escrita de mi participación en la Feria Internacional del Libro de la ciudad de Guadalajara. La presentación de Secretos fracturados tuvo lugar el día 7 de diciembre de 2019. Agradezco a Fernando M. González por la invitación, así como a Alberto Athié, quien también participó en el acto. Una segunda presentación tuvo lugar, de manera virtual, en la Feria Universitaria del Libro de la Universidad Autónoma del Estado de Hidalgo, el 2 de septiembre de 2020. Algunas ideas del texto son resultado del diálogo que tuvo lugar durante y después de la presentación de Guadalajara, así como de conversaciones con Pahola Sánchez Vega, Saúl Espino Armendáriz y Guillermo Zermeño Padilla. Agradezco las observaciones de quienes dictaminaron el texto en el anonimato.

Historia y Grafia, Universidad Iberoamericana, año 29, núm. 57, julio-diciembre 202I, pp. 357-365 
zación de las organizadoras, quienes acusaron que se trataba de una forma de censura, el foro finalmente se llevó a cabo. En la carta de motivos para la suspensión del evento, las autoridades del ITESO argumentaron que "no existen las condiciones de respeto para dicho foro". Esto fue corroborado por algunas participantes, quienes dijeron haber recibido amenazas. Incluso se rumoró que algunos de sus detractores se habrían organizado para ingresar al campus y "reventar el diálogo". ${ }^{2}$ Para quien no esté familiarizado con la historia del catolicismo tapatío en el siglo xx, esta referencia puede parecer una nimiedad. Sin embargo, el clima de tensión y de amenazas desde cierta derecha católica hacia una universidad jesuita invocaba a un espectro que no ha dejado de rondar el presente mexicano. En este caso, las disputas parecían invocar al fantasma de los Tecos, aquella organización secreta que, en 1958, intentó tomar por asalto las instalaciones del ITESO.

Michel de Certeau llegó a decir que la función de la historia era exorcizar al pasado, el cual suele asediar y atemorizar al presente. ${ }^{3}$ Siguiendo esta metáfora, podríamos pensar en Secretos fracturados como una suerte de exorcismo, y, como en los viejos manuales de demonología, esto sólo es posible si se conoce el nombre del espíritu que se busca conjurar. En este caso, no se trata de "la derecha", de "la Iglesia", del "clero" o de "los conservadores", sino del espectro, una organización que terminó por distanciarse de dos instituciones que, si bien no fueron sus creadoras, si fueron la condición de posibilidad de su existencia: la Compañía de Jesús y la propia Iglesia Católica, Apostólica y Romana. Secretos fracturados es la historia de la Asociación Fraternaria de Estudiantes de Jalisco (AFEJ), mejor conocida como Los Tecos. Las dos décadas que van de su fundación en los años treinta al asalto al ITESo en

${ }^{2}$ Judith Morán, “\#ITESOSÍDialoga sobre el derecho a decidir", 1 de octubre de 2018, Cruce, texto consultado en la web: <https://cruce.iteso.mx/itesosidialoga-sobre-el-derecho-a-decidir/> el 2 de diciembre de 2019.

${ }^{3}$ Michel de Certeau, La escritura de la historia, México, Universidad Iberoamericana, 2001, pp. 15-20. 
los años cincuenta, condensan un conjunto de discursos, prácticas y representaciones que han habitado la orden jesuita dentro de tres estratos temporales: la historia de los Tecos, las del conflicto religioso y uno que se remonta a sus orígenes.

El estrato más profundo es una marca casi omnipresente en el mundo cristiano. Lo que hoy llamamos antisemitismo, antes que una connotación racial, tenía más bien que ver con la alteridad religiosa representada por el judaísmo. Un momento clave en la historia del antijudaísmo tuvo lugar a finales del siglo Xv, con la unificación de los reinos de Castilla y Aragón, la creación del tribunal inquisitorial del imperio español y el decreto de conversión o expulsión hacia los judíos. Esta postura iba en contra de una vieja tradición que, por un lado, veía al pueblo hebreo como depositario de una hebraicas veritas, y por otro, enfatizaba el carácter misionero del cristianismo, al no hacer distinción entre los cristianos viejos y los recién convertidos. Ignacio de Loyola optó, a contracorriente de su tiempo, por apegarse a esta última visión, e instituyó una orden que no debía negar el acceso a los judíos conversos. Sin embargo, los certificados de pureza de sangre comenzaron a exigirse en la Compañía en los años siguientes. En el siglo XviI se dio una disputa por la memoria de la Orden. La provincia de Toledo solicitó que fuera borrada de la historia oficial la referencia al origen judío de algunos jesuitas de las primeras generaciones. Esa tensión acompanó a la Compañía a lo largo de los siglos. Para el xIX aparecieron algunos textos jesuitas en La Civiltà Cattolica, órgano romano de la Orden, los cuales condensaban el viejo discurso que acusaba a los judíos de ser un pueblo deicida, las antiguas representaciones de la usura y la avaricia, la tesis del complot masónico que emergió con la Revolución francesa, y las modernas teorías que ubicaban el mal del pueblo judío no sólo en sus creencias y prácticas religiosas, sino también en la naturaleza de su raza. De alguna manera, en esos discursos convergía el antiguo antijudaísmo cristiano, de carácter religioso, con el antisemitismo moderno, fundado en concepciones y teorías raciales. 
Un segundo estrato refiere al enfrentamiento entre la Iglesia católica y el régimen revolucionario, más allá del episodio conocido como la Cristiada. En estos años aparecieron dos elementos que habrán de conformar el "desenlace" de esta historia: el surgimiento de sociedades secretas católicas y la cercanía de algunos jesuitas a dichos sectores radicales, cuya relación se dio en un plano más bien cercano a la reserva y la clandestinidad. Ambos temas introducen un matiz importante. Al igual que con el antisemitismo, no es posible hablar de una posición uniforme de la Compañía. Muchos jesuitas respaldaron el levantamiento armado, pero también mostraron reservas frente a la "U", la primera sociedad secreta del catolicismo mexicano, entre otras cosas, por la independencia con la que se movía y por sus pretensiones de dirigir el movimiento, a diferencia de la Liga Nacional de la Defensa de la Libertad Religiosa, que ellos asesoraban.

Aunque las prácticas y formas de sociabilidad surgidas en este estrato temporal no implican un vínculo mecánico entre jesuitas y sociedades secretas, dejan ver la formación de una cultura política peculiar. Ante la derrota de la Cristiada, muchos católicos vieron la clandestinidad como una vía legítima. Esto ocurrió simultáneamente a la creación de la Acción Católica Mexicana (ACM) o los partidos de inspiración católica. A esto habría que añadir un matiz conceptual propio del lenguaje eclesiástico, que distinguía entre las sociedades "secretas", tales como la masonería, que fueron condenadas desde el siglo xix, y las "discretas" o "reservadas" que, aunque muy parecidas, contaban con mecanismos de supervisión por parte de la jerarquía católica. Secretos fracturados puede leerse como un diálogo con trabajos como La formación social y politica de los católicos mexicanos de María Luisa Aspe, ${ }^{4}$ pues da cuenta de la diseminación de prácticas y posicionamientos políti-

${ }^{4}$ María Luisa Aspe Armella, La formación social y politica de los católicos mexicanos. La Acción Católica Mexicana y la Unión Nacional de Estudiantes Católicos, 1929-1958, México, Instituto Mexicano de Doctrina Social Cristiana/Universidad Iberoamericana, 2008. 
cos que significaron los arreglos que pusieron fin a la Cristiada en 1929, cuando la premisa del episcopado mexicano y del Vaticano era trabajar por restaurar un orden social cristiano, aunque la vía armada y la política partidista católica quedaron proscritas.

El tercer estrato es el de un proceso que va de los años treinta a los cincuenta, y que tiene que ver propiamente con la historia del AfEJ, fundada en Guadalajara por Carlos Cuesta Gallardo y Antonio Leaño. Esta organización abreva del discurso antisemita condensado a finales del siglo XIX como una suma de representaciones deicidas, raciales y de conspiración mundial, así como de las prácticas de secrecía que tomaron forma en el México (post) cristero. Buena parte de la argumentación gira alrededor del hecho de que varios jesuitas supieron de la naturaleza de este grupo desde sus orígenes, aunque optaron por actuar como si no. Así, las autoridades de la Orden permitieron que José Figueroa Luna, un religioso que compartía el anticomunismo y la tesis de la conspiración judeomasónica de los Tecos, participara en el reclutamiento de estudiantes para la organización en el Instituto de Ciencias, el colegio jesuita de Guadalajara. A pesar de ello, mostraron sorpresa al enterarse de las amenazas que los Tecos lanzaron ya en los cincuenta.

El proceder de la Compañía ante la actividad del padre Figueroa, una vez que se volvió problemática, fue su deslocalización geográfica. Dese 1952 había dos provincias jesuitas en México, y Figueroa fue transferido de una a otra, de Guadalajara a Puebla. Las autoridades del Occidente no se molestaron en mencionar sus antecedentes en aquella ciudad, y las del Oriente no preguntaron. Al poco tiempo de haberse instalado, Figueroa comenzó un trabajo similar entre las juventudes poblanas, especialmente con las congregaciones marianas y el Instituto Oriente, colegio jesuita de la ciudad. El resultado fue el surgimiento de una nueva sociedad secreta. El Yunque no sólo contó con la asesoría del padre Figueroa y con la de los propios fundadores de los Tecos, Leaño y Cuesta Gallardo. 
El año de 1958 marca una coyuntura en la historia del mundo católico. La llegada al papado de Juan XXIII inauguró los aires de renovación que condujeron al Concilio Vaticano II, lo cual despertó sospechas, reticencias y resistencias en los sectores más conservadores. También, como ha señalado María Luisa Aspe, marca un momento de declive en la ACM, la principal organización católica del periodo postcristero. Por último, como se narra al final de Secretos fracturados, en ese año ocurrió una serie de acontecimientos que marcó el desenlace de esta historia y la apertura de otras: la fundación del ITESO; el asalto a sus instalaciones por parte de los Tecos y su respectiva condena por el arzobispo José Garibi Rivera, quien ese mismo año se convirtió en el primer cardenal mexicano; y el fallecimiento de José Figueroa Luna en Puebla. El asalto se explica por la mirada delirante de Cuesta Gallardo y de los Tecos, quienes reprodujeron su tesis de la conspiración mundial a escala local. Desde su perspectiva, el mundo en el que vivían se encontraba dominado por un grupo secreto infiltrado en las principales instituciones católicas. Esto ocurría en el momento en que se remarcaban algunas fracturas dentro del catolicismo jalisciense, ya que algunas familias buscaban una opción educativa alternativa a la Universidad de Guadalajara y a la Universidad Autónoma de Guadalajara, cuya escisión se remonta a las pugnas entre la educación socialista, la libertad de cátedra y la autonomía universitaria. La fundación del ITESo fue vista como una subversión desde el interior del catolicismo, operada por Efraín González Luna, fundador del Partido Acción Nacional en Jalisco. En los años siguientes, el campo católico quedó aún más escindido con la recepción del Concilio Vaticano II. Algunos jesuitas y otros miembros del clero regular se movieron hacia la izquierda, con algunas radicalizaciones incluidas, mientras que ciertos defensores de la ortodoxia interpretaron al Concilio como resultado de la infiltración judeomasónica. Los Tecos terminaron integrándose a las ramas tradicionalistas del catolicismo romano, desconociendo las reformas conciliares y declarando "Sede Va- 
cante” en Roma. Esto los llevó a romper con el grupo que surgió como su espejo poblano, pues el Yunque permaneció dentro del redil romano. ${ }^{5}$

Más que evaluar la información recopilada por el autor, ya sea por medio de documentos o de entrevistas, quisiera llamar la atención sobre dos aspectos que, en mi opinión, dan cuenta de las dificultades metodológicas para lidiar con un objeto de estudio tan elusivo. El primero tiene que ver con el carácter paradójicamente espectral de su objeto de estudio. Uso esta expresión porque, a pesar de las pretensiones de los Tecos de hacerse presentes sin ser visibles en numerosos ámbitos de la vida social y política de Guadalajara, han sido, como señala el autor "la sociedad secreta más pública” de esa ciudad. Esto representa un reto metodológico, pues implica ir tras unas huellas que han sido borradas con intención, de ahí que la información aparece fragmentada y dispersa. El título refiere a una historia donde el pasado resulta accesible en exclusiva atendiendo a los silencios, a los lapsus y a "las distintas maneras de no decir”. Más que ante evidencias, estamos ante un conjunto de indicios recogidos y tejidos en una narración que, como el propio autor señala, no representa sino una entre muchas posibilidades narrativas. Sin embargo, el texto sitúa al lector en una puesta en abismo cuando le permite ver que el historiador no sólo busca exorcizar un espectro, sino que éste, a su vez, remite a un conjunto de actores que pasaron su vida a la caza de un fan-

${ }^{5}$ Véanse las siguientes tesis defendidas en el Instituto Mora: Mónica Naymich López Macedonio, "Los Tecos en el México de la primera mitad de los años setenta y su proyección trasnacional anticomunista”, tesis de maestría en Historia Moderna y Contemporánea, México, Instituto Mora, 2007; Austreberto Martínez Villegas, "Tradicionalismo y conservadurismo integrista en el catolicismo en México después del Concilio Vaticano II: continuidades y transformaciones en Guadalajara, Jalisco y Atlatlahuacan, Morelos (1965-2012)", tesis de maestría en Historia Moderna y Contemporánea, México, Instituto Mora, 2007; y Mario Virgilio Santiago Jiménez, "Entre el secreto y las calles. Nacionalistas y católicos contra la 'conspiración de la modernidad': El Yunque de México y Tacuara de Argentina (1953-1964)", tesis de maestría en Historia Moderna y Contemporánea, México, Instituto Mora, 2007. 
tasma: la conspiración judeomasónica. Si el espectro, siguiendo a Jacques Derrida, remite a una figura situada en el umbral del pasado y del presente, a un elemento del pasado que no termina de irse, el fantasma refiere a una categoría psicoanalítica que nombra a aquellas fantasías que no necesitan ser "reales" para incidir en la vida del sujeto.

Finalmente, recupero una discusión que aparece en una de las entrevistas realizadas por el autor. En un diálogo que estableció con Xavier Cacho S. J., a propósito de la relación de Figueroa Luna con los Tecos, el jesuita dijo al autor: "Pero hay que pensar que a la generación de Figueroa le había tocado el abuso del cierre de las iglesias, luego la Cristiada, después la educación socialista y ahora que comenzaba la radicalización del marxismo, pues no le hizo mucha gracia. No hay que hacer anacronismos y, como decía O'Gorman, terminar 'regañando a los muertos'”. La respuesta del autor es que: "En efecto. No se trata de 'regañar a los muertos', pero en ciertos casos es de ayuda matizar las afirmaciones de los vivos" (pp. 564-565). En el capítulo III de la segunda parte del libro hay una referencia a la primera reunión de padres provinciales de la Compañía de Jesús que tuvo lugar en México en 1946. En ella, Mariano Cuevas dijo que era necesario tomar providencias para procurar que la historia de la Orden fuera escrita, ya por jesuitas o ya por historiadores autorizados por la Compañía, evitando que quedara en manos de historiadores "heterodoxos" (pp. 389-390).

Tanto Mariano Cuevas como Xavier Cacho se cuentan entre los historiadores jesuitas del siglo xx mexicano. La discusión que Fernando González establece con ellos remite a la complicada relación que el catolicismo ha tenido con el saber histórico en los últimos siglos. Cuevas y Cacho remiten a dos momentos de la historia eclesiástica mexicana y a dos maneras en que ésta asimiló los procedimientos historiográficos modernos. Cuevas se mantuvo apegado a la forma tradicional de la historia eclesiástica, una rama de la teología cuyo discurso debía mantenerse a salvo de 
la heterodoxia. Otros historiadores de su generación, como José Bravo Ugarte, abrevaban de la renovación que León XIII impulsó en la Universidad Gregoriana, adoptando procedimientos de la ciencia histórica moderna. Cacho pertenece a una generación que había asimilado muchos de esos presupuestos. Su referencia a O'Gorman es un llamado a mantener la distancia y evitar juicios sobre un pasado con valores distintos a los del presente. Pero los parámetros desde los cuales se establece la distinción entre pasado y presente no son siempre claros. Aun si lo fueran, el carácter espectral del pasado nos recuerda que esta forma de escritura no sólo refiere a los muertos, sino a aquello que éstos nos han dejado como herencia. Secretos fracturados es la historia tanto de los Tecos, como la de cómo algunos católicos han lidiado con ciertos elementos de su pasado que con dificultad pueden ser asimilados como parte de una tradición. La brecha entre la tradición heredada y el futuro esperado comenzó a abrirse aun más precisamente en 1958. Como deja ver en las últimas páginas, la propia trayectoria del autor se desprende de alguna manera de esa historia. Su escritura es resultado de esa ruptura en las formas de dar cuenta de los pasados católicos que no terminan de pasar.

Hasta hace unos años, el tema abordado en este libro había sido motivo más bien de rumores, susurros, y a veces de textos periodísticos. Hoy es motivo de investigaciones históricas. Toca al lector decidir qué tan eficaz es este exorcismo, pues como Michel de Certeau escribió en La posesión de Loudun, "la historia nunca es confiable". ${ }^{6}$ Los espectros que intentamos exorcizar seguirán habitándonos. Quizá la escritura ayude, si no a dejarlos atrás, al menos a aprender a vivir con ellos. 雪

${ }^{6}$ Michel de Certeau, La posesión de Loudun, México, Universidad Iberoamericana, 2012, p. 21. 